\title{
The Effects of Pressure and Temperature on Partial Discharge Degradation of Silicone Conformal Coatings
}

DOI:

10.1109/TDEI.2017.006466

\section{Document Version}

Accepted author manuscript

Link to publication record in Manchester Research Explorer

\section{Citation for published version (APA):}

Emersic, C., Lowndes, R., Cotton, I., \& Rowland, S. (2017). The Effects of Pressure and Temperature on Partial Discharge Degradation of Silicone Conformal Coatings. IEEE Transactions on Dielectrics and Electrical Insulation, 24(5), 2986-2994. https://doi.org/10.1109/TDEl.2017.006466

\section{Published in:}

IEEE Transactions on Dielectrics and Electrical Insulation

\section{Citing this paper}

Please note that where the full-text provided on Manchester Research Explorer is the Author Accepted Manuscript or Proof version this may differ from the final Published version. If citing, it is advised that you check and use the publisher's definitive version.

\section{General rights}

Copyright and moral rights for the publications made accessible in the Research Explorer are retained by the authors and/or other copyright owners and it is a condition of accessing publications that users recognise and abide by the legal requirements associated with these rights.

\section{Takedown policy}

If you believe that this document breaches copyright please refer to the University of Manchester's Takedown Procedures [http://man.ac.uk/04Y6Bo] or contact uml.scholarlycommunications@manchester.ac.uk providing relevant details, so we can investigate your claim.

\section{OPEN ACCESS}




\title{
The Effects of Pressure and Temperature on Partial Discharge Degradation of Silicone Conformal Coatings
}

\author{
Christopher Emersic ${ }^{1}$, Robert Lowndes ${ }^{2}$, lan Cotton', Simon Rowland ${ }^{1}$ \\ and Robert Freer ${ }^{2}$ \\ ${ }^{1}$ School of Electrical and Electronic Engineering (EEE) \\ ${ }^{2}$ School of Materials \\ The University of Manchester, Manchester, United Kingdom
}

\begin{abstract}
The partial discharge damage rates for silicone-coated printed circuit boards have been quantified in a series of experiments at pressures and temperatures relevant to the aerospace industry (down to $116 \mathrm{mbar},-55^{\circ} \mathrm{C}$ to $+70^{\circ} \mathrm{C}$ ) and up to $6 \mathrm{kV}$. Surface cracking was observed, and damage magnitude was found to be non-linear with coating thickness, with thinner coatings experiencing relatively greater damage rates. This is attributed to higher surface electric fields for a given energisation voltage. Increasing temperature or reducing pressure increased the rate of damage. For coating thicknesses less than $100 \mu \mathrm{m}$, reducing pressure to $116 \mathrm{mbar}(1 \mathrm{mbar}=100 \mathrm{~Pa})$ increased the relative crack growth rate by nearly an order of magnitude. Temperature change had the most profound influence on damage; low temperatures were observed to substantially reduce damage rate, with very little or no damage observed, whereas higher temperatures substantially increased damage rate, with the resulting magnitude of surface damage too large to quantify. Silicone coatings of thickness greater than $250 \mu \mathrm{m}$ showed no appreciable damage from partial discharge when aged at either low pressure or high temperature at voltages up to $6 \mathrm{kV}$. Corresponding damage-free surface electric fields are computed. No samples were observed to fail, indicating the robustness of high quality silicone coatings. Possible causes of crack formation in silicone are discussed.
\end{abstract}

Index Terms - Aerospace testing, Partial discharges, Coatings, Aircraft power systems, Power electronics

\section{INTRODUCTION}

THERE is an increasing use of higher voltage systems in aerospace applications. These systems can be vulnerable to partial discharge, particularly given the low operating air pressure [1]. Power electronic systems are being placed in locations of the aircraft that results in exposure to a range of environments. In these locations, the air pressure can typically reach values of $116 \mathrm{mbar}(1 \mathrm{mbar}=100 \mathrm{~Pa})$ (equivalent to an altitude of 50,000 feet or $15,240 \mathrm{~m}$ ) and temperatures can fall below $-50^{\circ} \mathrm{C}$ [2]. The insulation system must tolerate these environmental stresses in the presence of increasingly greater electric fields, given industry desire to achieve greater power densities whilst operating at higher voltages and the need for device compaction [3-5]. As such, it is critical to better understand the risks associated with polymer conformal-coated printed circuit boards and other similar systems within the power

Manuscript received on 28 November 2016, in final form 27 April 2017, accepted 14 June 2017. Corresponding author: C. Emersic. electronic converter operating at high voltages. In particular, when operating at lower pressures, conformal coatings are at greater risk of degradation given the lower partial discharge inception voltages that result in such systems [1].

Very few studies have looked at the degradation of silicone coatings on power electronics due to partial discharge at low pressure. Karady et al. [6] examined the effects of partial discharge at low pressures and found a strong correlation between electric field strength and the extent of the damage on relatively complex test boards. Deterioration continued in their tests of up to 200 hours; however, the rate was not quantified. Sili et al. [7] looked at polyimide coating lifetime when aged by partial discharge (corona spray) as a function of pressure, temperature, and humidity. They observed that failure of their samples occurred earlier with reducing pressure or increasing temperature because of increased partial discharge energy.

In related experimental investigations preceding this study [8], the degradation of silicone coated boards exposed 
to partial discharge was characterised. Observations indicated that the partial discharge in the samples under test was principally a surface-based phenomenon, and was influenced strongly by pressure. It was also found that coating thickness strongly influenced the rate of degradation (crack formation), with coating thicknesses below $60 \mu \mathrm{m}$ providing minimal protection, and those above $180 \mu \mathrm{m}$ providing the greatest levels of protection at ambient pressure and temperature.

This study expands on the laboratory investigations previously reported in [8] and quantifies the rate of damage to silicone coatings as a function of pressure and temperature within the limits found in operational airborne systems.

\section{EXPERIMENTAL DESIGN}

A detailed description of the experimental setup is provided in [8], with a summary provided here. Test boards consisted of a simple design comprising two mirror-curved tracks. The bare boards and tracks were cleaned prior to coating, which involved soaks in an ultrasonic bath of ammonia solution and dipping in isopropyl alcohol before drying. The coating process involved dipping into silicone $1 \mathrm{C} 49$ (HumiSeal ${ }^{\circledR}$ ) and curing for 24 hours in ambient air before being stored in a sealed environment prior to testing. Coatings were of high quality and void free. For the samples used in this study, the coating thicknesses ranged from approximately $100 \mu \mathrm{m}$ to greater than $200 \mu \mathrm{m}$, with variation resulting from pooling during the curing process while boards were mounted vertically.

The experimental test circuit is illustrated in Figure 2.1. Testing was performed in an environmental chamber using a $50 \mathrm{~Hz}$ sinusoidal AC voltage signal. Pressures and temperatures were adjusted after samples were inserted in the chamber, and sufficient time was allowed to ensure thermal equilibrium had been reached. The chamber is not
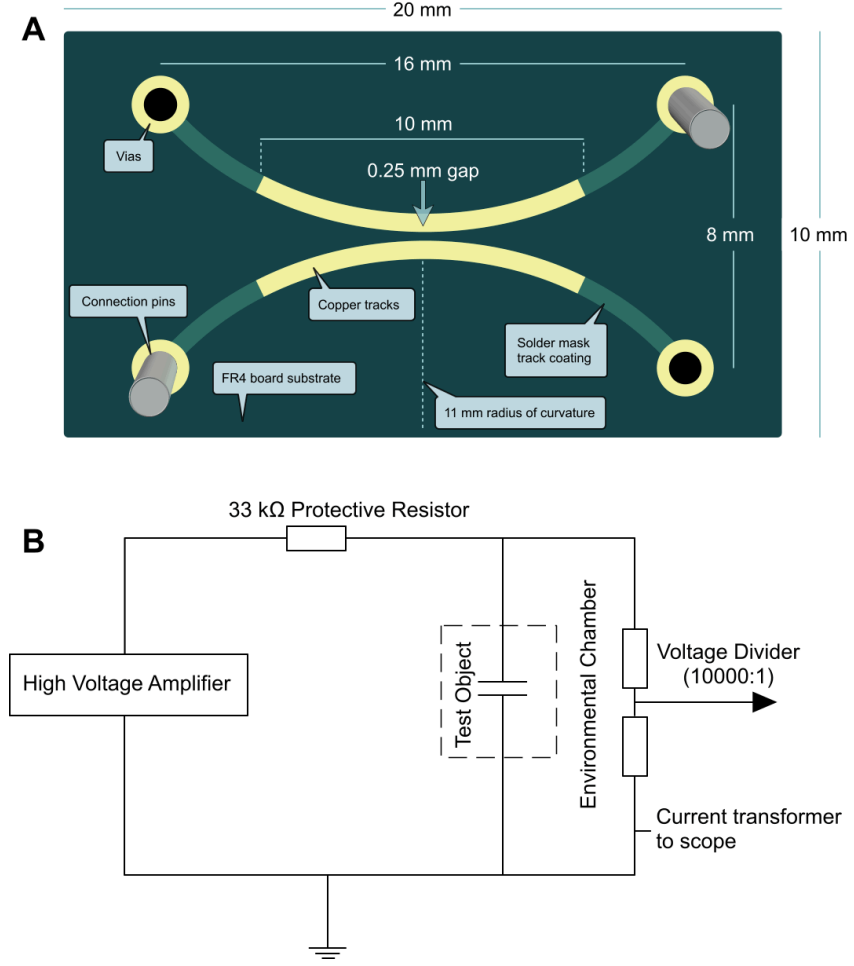

Figure 2.1.Test boards and sketch of the experimental test circuit. hermetically sealed and thus air within the chamber can be exchanged with the ambient environment, ensuring there is no build-up of ozone or similar by-products of the partial discharge process. The test voltage was increased at a rate of $100 \mathrm{~V} \mathrm{~s}^{-1}$ until partial discharges were detected via the high frequency current transformer on the earth line, which fed the discharge signals to an oscilloscope. As with the earlier investigation, partial discharge was thus produced by energising the tracks on the boards rather than being externally applied through corona spray. For a given experiment, ten identical sample boards were energised together in parallel and left to age under active partial discharge for up to approximately 160 hours. The boards were spatially separated to ensure there was no influence from neighbouring boards. Sample boards were briefly removed approximately every 24 hours for measurement of coating damage using optical microscopy. Only the combined partial discharge signal from all samples was monitored here; contributions from individual sample could not be resolved given that multiple samples of varying thicknesses were energised and aged simultaneously. The properties of the partial discharges were not of focus; only that partial discharge was occurring. Confidence that partial discharge was occurring on all samples was achieved by raising test voltages considerably above initial inception and observing subsequent progressive degradation in the coatings.

Four sets of experiments were conducted to test the effects of varying pressure and temperature. Two experiments were conducted at ambient temperature at pressures of $500 \mathrm{mbar}$ and $116 \mathrm{mbar}$, with two further experiments conducted at ambient pressure at temperatures of $-55^{\circ} \mathrm{C}$ and $+70^{\circ} \mathrm{C}$. Aging voltages of $4.0 \mathrm{kV}$ and $1.7 \mathrm{kV}$ were used for experiments at $500 \mathrm{mbar}$ and $116 \mathrm{mbar}$ respectively as they were comfortably above inception without leading to breakdown. All voltage values listed here are peak voltage unless otherwise stated. At $-55^{\circ} \mathrm{C}$, stable partial discharge was initially achieved at $4.3 \mathrm{kV}$ but the test voltage required to maintain a consistent discharge level was later increased to $5.0 \mathrm{kV}$ after 42 hours, and then $5.5 \mathrm{kV}$ after 136 hours. At $+70^{\circ} \mathrm{C}$, a voltage of $4.3 \mathrm{kV}$ was applied, but this was increased to $6.0 \mathrm{kV}$ after 23 hours to provide confidence that comparable levels of partial discharge were being produced based on the oscilloscope output.

When samples which had been aged at low temperature were removed for microscopy, they were gently heated using warm air to melt ice and remove all condensation without physical contact with the coating surfaces. This introduced a small amount of surface dust to the samples but this was not observed to influence any electrical phenomena, consistent

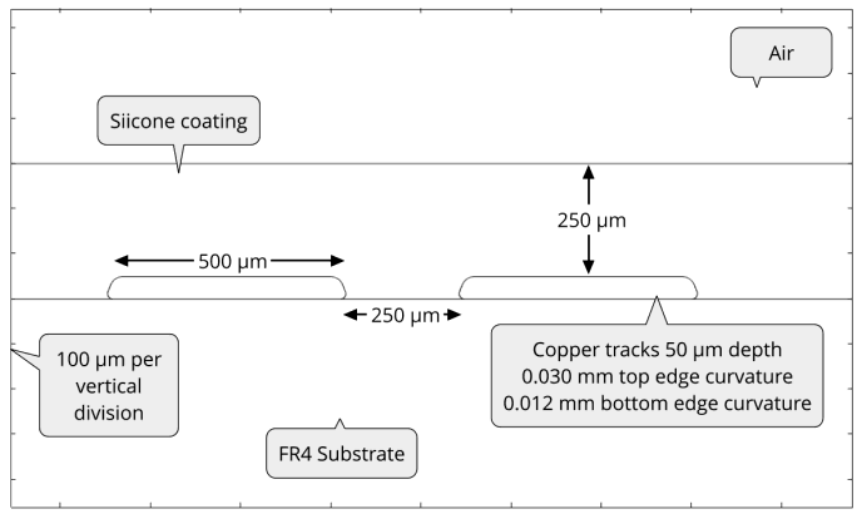

Figure 2.2. Image of COMSOL model geometry used in simulations. 


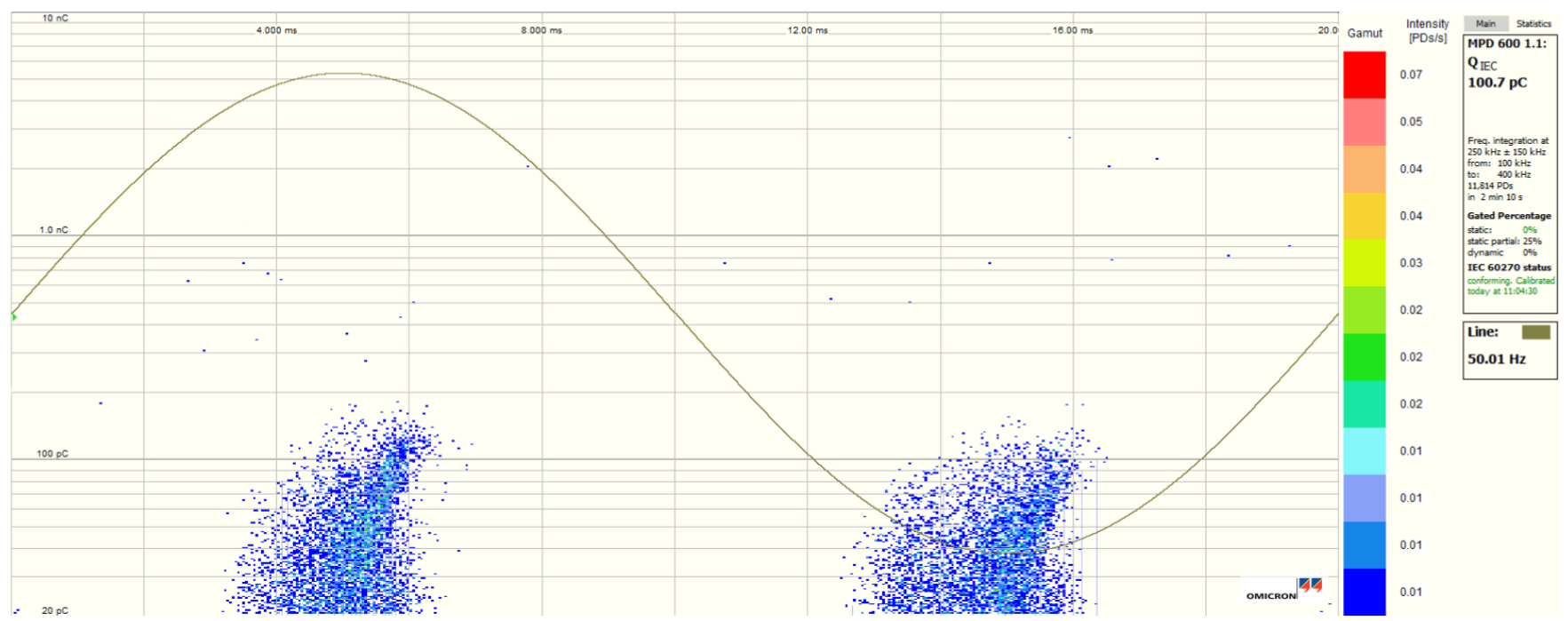

Figure 3.1. Typical phase-resolved partial discharge plot of an individual energised sample at $116 \mathrm{mbar}$.

with observations in our earlier related investigation.

\subsection{MODELLING SIMULATIONS}

In addition to the experimental work, a $2 \mathrm{D}$ model of the cross section of the test samples was created in COMSOL Multiphysics to perform finite element analysis and computation of the surface electric fields. Figure 2.2 shows the model geometry used, which was based on microscopy of test samples that had been cut through the centre where the tracks are closest (Figure 2.1 A). Simulations were performed using a coating thickness of $250 \mu \mathrm{m}$ with a potential difference between tracks of up to $6 \mathrm{kV}$.

\section{OBSERVATIONS AND DISCUSSION 3.1 EFFECTS OF PRESSURE}

Partial discharge was observed to initiate at lower voltages with reducing pressure, as would be expected [1]. Stable partial discharge at ambient pressure occurred at approximately 4.25 to $4.5 \mathrm{kV}$ in the related previous study [8], whereas here at $500 \mathrm{mbar}$, this reduced to $4.0 \mathrm{kV}$, and to $1.7 \mathrm{kV}$ at 116 mbar. This pressure dependence is consistent with the earlier findings that partial discharge is occurring on the surface-air interface of the silicone coatings. Figure 3.1 shows a typical phase-resolved plot for an individually tested sample experiencing partial discharge at 116 mbar,

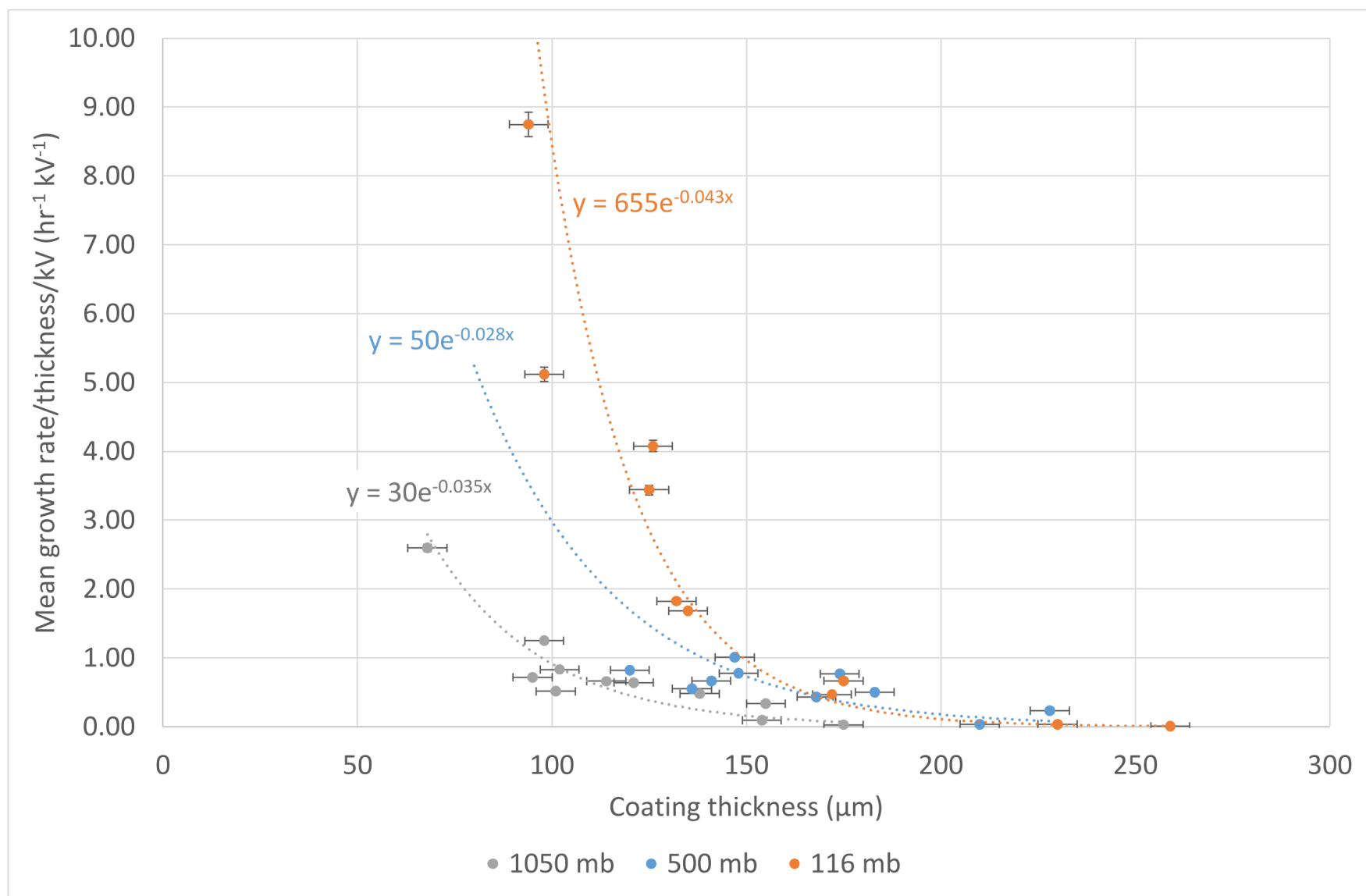

Figure 3.2. Relationship between silicone coating surface crack growth rate (normalised to coating thickness and test voltage) and coating thickness, as a function of pressure. (1050 mbar data adapted from [8].) 
again revealing comparable magnitude partial discharges occurred at the peaks of both sides of the AC voltage cycle, indicating surface based discharges.

The cracking was determined to be surface-based using focus changes under microscopy, extending approximately $20 \mu \mathrm{m}$ into the coating in all samples (including alterative test conditions discussed later), consistently with earlier findings. Figure 3.2 shows the relationship between crack growth rate and coating thickness as a function of pressure. Crack growth was measured optically in software by measuring the additional total crack length gained between microscopy observations. During testing, the voltage at which stable partial discharge occurred varied between samples. Control over coating thickness was not possible to ensure comparable thicknesses between samples. Thus, growth rate has been normalised per unit thickness per unit test voltage. Figure 3.2 shows damage rate is non-linear with coating thickness, and is described reasonably well by an exponential function. Note the trend line has been extrapolated for $500 \mathrm{mbar}$ as test samples were not available with thinner coatings during that test. Thinner coatings experience considerably greater degradation from partial discharge. This is consistent with our previous investigation which concluded that this was a result of the increased surface electric fields for a given test voltage (note that ambient pressure data is taken from [8]). A strong pressure dependence on damage rate is also observed, with the effect enhancing further the severity of degradation as coating thickness reduces. For coating thicknesses less than $100 \mu \mathrm{m}$, the damage rate at $116 \mathrm{mbar}$ was almost an order of magnitude greater than at ambient pressure. Our previous research showed that silicone coating thicknesses greater than $180 \mu \mathrm{m}$ provided maximal protection from degradation at ambient pressure. At lower pressures, more substantial degradation was observed to thicknesses of $225 \mu \mathrm{m}$, with the equivalent maximal protection (minimal degradation) provided at thicknesses above approximately $250 \mu \mathrm{m}$. None of the test samples here suffered breakdown and failed.

The enhanced rate of damage at lower pressures is likely to be due to the reduced relative air density and associated inversely proportional mean free path of partial discharge electrons which provides greater energy, as discussed by Sili et al. [7]. This results in more aggressive chemical degradation and particle bombardment, which are considered the principal methods of polymer degradation from partial discharge [9].

\subsection{EFFECTS OF TEMPERATURE}

Temperature was observed to have a dramatic influence on the severity of degradation of the silicone coatings. At a temperature of $-55^{\circ} \mathrm{C}$, seven of the ten samples showed no evidence of degradation despite a comparable thickness range and applied voltages of equal to or greater than those applied at ambient temperature. Note that aging voltage was increased from 4.3 to $5.5 \mathrm{kV}$ during testing to maintain stable partial discharge when subsequently reenergised after microscopy. Voltage was not varied after aging continued to determine whether this was transient or could be lowered back to initial values in the interest of experimental reproducibility. The three samples which did show crack formation in the coating had normalized growth rates per unit thickness of 0.04 to $0.07 \mathrm{hr}^{-1} \mathrm{kV}^{-1}$ and very little total cracking. These samples had the thinnest coatings of 103,
113, and $116 \mu \mathrm{m}$ (Table 1) and would thus be expected to show the greatest degradation, which is consistent with earlier conclusions about the influence of coating thickness. It should be noted that the absence of damage on the thicker coated samples is possibly because there is no partial discharge activity (this couldn't be measured on individual samples). This possibility seems unlikely because the level of total partial discharge activity on the oscilloscope output was comparable, and test voltages were at values that similar samples at ambient temperature had produced measurable partial discharge.

An additional observation revealed an undulating pattern forming on sample coatings (Figure 3.3). This pattern was also seen to change completely each time the sample was removed from the chamber for microscopy. Initially it was not clear whether this surface pattern was caused by or was influencing the degradation process. A subsequent investigation was made in which a virgin test sample was placed in the environmental chamber at $-55^{\circ} \mathrm{C}$ without any electrical testing. This sample also exhibited the same undulating pattern on the silicone surface, thus confirming that this patterning is not caused by electrical activity. It is possible that the undulations and corresponding small thickness changes are a result of inhomogeneous temperature changes and thermal expansion of the silicone when the sample is removed from the low temperature environment to ambient temperature for microscopy. The sample was also subjected to gentle heating and air blowing from a hair dryer to evaporate water droplets, formed from condensation and melted ice crystals, which may have contributed to a more rapid temperature increase and differential thermal expansion. When samples that developed this patterning were returned to the low temperature environment, the thermal contraction of the silicone may have restored a flatter surface. The patterning then formed again during subsequent reheating and thermal expansion prior to microscopy, thus explaining the different

Table 1. Sample silicone coating thicknesses and growth rates at the two test temperatures. Severe coating cracking at high temperature on most samples prevented measurement of crack growth rates.

\begin{tabular}{|c|c|c|}
\hline $\begin{array}{c}\text { Temperature } \\
\left({ }^{\circ} \mathbf{C}\right)\end{array}$ & $\begin{array}{c}\text { Sample coating } \\
\text { thickness }(\boldsymbol{\mu m})\end{array}$ & $\begin{array}{c}\text { Av. growth/thickness } \\
\mathbf{l k V}(\mathbf{h r} / \mathbf{k V})\end{array}$ \\
\hline-55 & 142 & 0.00 \\
& 129 & 0.00 \\
& 155 & 0.00 \\
& 103 & 0.04 \\
& 227 & 0.00 \\
& 159 & 0.00 \\
& 179 & 0.00 \\
& 175 & 0.00 \\
& 113 & 0.07 \\
& 116 & 0.05 \\
\hline 70 & 121 & High \\
& 225 & 0.36 \\
& 148 & High \\
& 230 & 0.00 \\
& 140 & High \\
& 240 & 0.00 \\
& 135 & High \\
& 140 & High \\
& 75 & High \\
& 110 & High \\
\hline
\end{tabular}




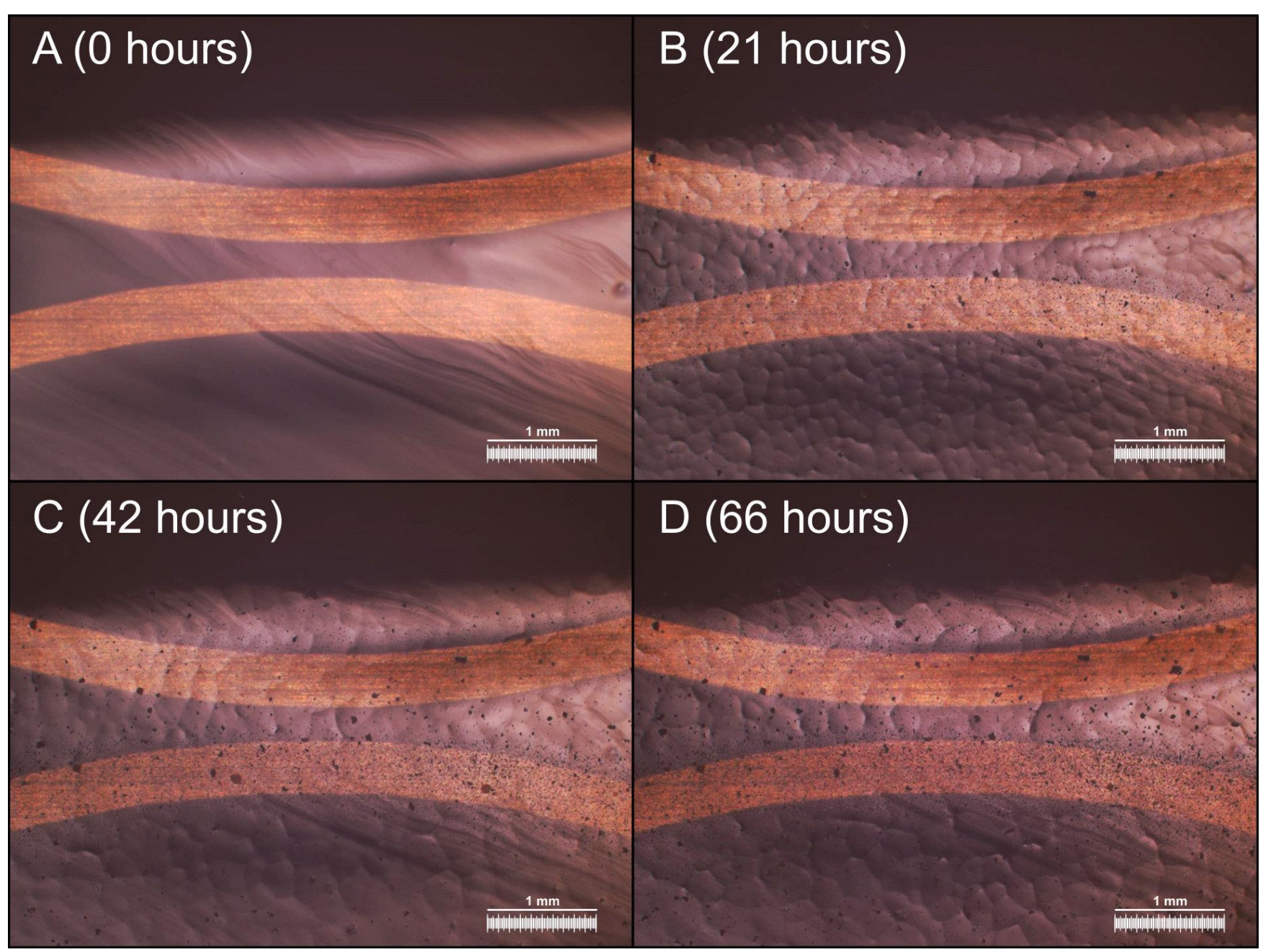

Figure 3.3. Evidence of surface texturing forming on a virgin $142 \mu \mathrm{m}$ coated sample (A) prior to the first microscopy sample (B). This texture pattern changed completely with each subsequent microscopy sample (C and D).

pattern formations. The likely loss of surface undulations during cooling makes it unlikely that the patterning influenced partial discharge or associated degradation.

The samples aged at $70^{\circ} \mathrm{C}$ showed rapid and substantial crack development (Figure 3.4). In seven of the ten samples, the magnitude of cracking was so severe that it prevented identification of individual cracks for quantification of crack growth rate during analysis. The crack growth rates in samples aged at $70^{\circ} \mathrm{C}$ are nevertheless substantially greater than those observed for samples at low pressure. Three samples degraded at much lower rates, and these were the samples which had the greatest thicknesses; a sample with thickness of $225 \mu \mathrm{m}$ showed no crack development initially, a greater rate of $0.91\left(\mathrm{hr}^{-1} \mathrm{kV}^{-1}\right)$ from 69 hours, and a mean of $0.36\left(\mathrm{hr}^{-1} \mathrm{kV}^{-1}\right)$. The remaining two samples with thicker coatings of 230 and $240 \mu \mathrm{m}$ showed no crack development. This again highlights the strong nonlinear response of degradation with thickness, even when damage rates are strongly enhanced by high temperatures. It should be noted that the aging voltage in the higher temperature tests was initially $4.3 \mathrm{kV}$, but increased to $6.0 \mathrm{kV}$ after 23 hours to ensure stable partial discharge. This is in contrast to the low temperature tests which initially aged at $4.3 \mathrm{kV}$, but was later increased to $5.0 \mathrm{kV}$ after 42 hours and then $5.5 \mathrm{kV}$ after 136 hours to achieve stable partial discharge. While the higher aging voltages will contribute to the enhanced rate of damage at higher temperatures, consistent with previous findings, it cannot fully account for the magnitude of the enhanced rate given that the maximum voltage remains comparable and there is still no damage to the samples with the thickest coatings. As with samples tested at low pressure, none of the samples tested at high or low temperature resulted in breakdown, even despite the severity of the observed degradation at high temperature.

During microscopy of one of the samples aged at $70^{\circ} \mathrm{C}$ that was cooling, the formation of a new crack was directly observed. The crack formed across the sample surface without any direct external influence in a timescale of approximately 1 second. This observation supports conclusions from our previous study [8] that at least some of the cracks which form are likely a consequence of a mechanical relaxation process within the silicone structure. Some cracks on these samples had a much greater width, but these did not penetrate any deeper than the $20 \mu \mathrm{m}$ observed for other cracks. The surface opening or fissure was simply wider, reaching approximately $100 \mu \mathrm{m}$ in some cases (Figure 3.5).

These observations of temperature-dependent coating damage may be accounted for in two ways. Firstly, increasing temperature will increase the energy that partial discharge electrons carry (amongst other gas constituents) Additionally, as with lower pressures, the relative air density at higher temperatures is reduced and is inversely proportional to the mean free path of the electrons. These two factors combined increase the energy carried by the 


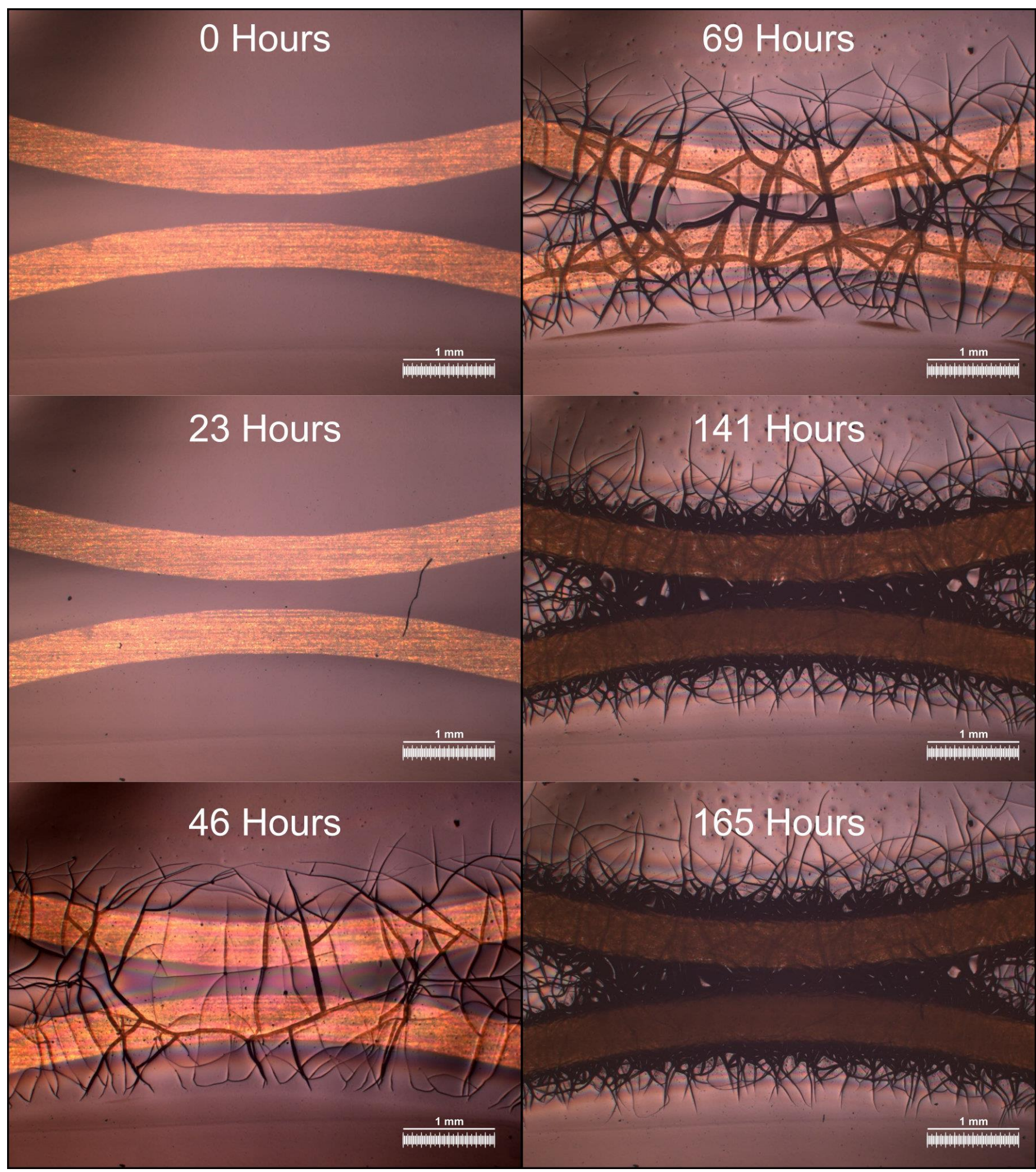

Figure 3.4. Micrograph timeline of severe damage on silicone coatings during partial discharge aging at $70^{\circ} \mathrm{C}$. Crack density in this $135 \mu \mathrm{m}$ sample was so high by 141 hours that identification of individual cracks, and thus quantification, was not possible.

electrons, thereby enhancing chemical degradation processes as they bombard the silicone [7, 9]. Secondly, increasing the equilibrium temperature of the material itself reduces the additional energy required from bombarding electrons to cause chemical degradation. Research conducted into electrical treeing has also concluded that insulation endurance is reduced at higher temperatures [10, 11]. Kim et al. [12] suggested that exposure to the oxidizing effects of partial discharge created a silica-like layer on the uppermost surface that can become porous and cracked. Based on observations here and in our previous related study [8], it would appear that mechanical stresses, such as those created by temperature changes during thermal equilibration, may also contribute to the initiation of these cracks-particularly as cracks were observed to form without direct coercion under the microscope shortly after removal of a sample from the $70^{\circ} \mathrm{C}$ environment when thermal contraction occurred.

\subsection{OTHER OBSERVATIONS}

In the preceding study [8], the formation of a black substance was observed on the surface of samples during the aging process. This was suspected to be particles of ambient aerosol being electrostatically attracted to the energized 


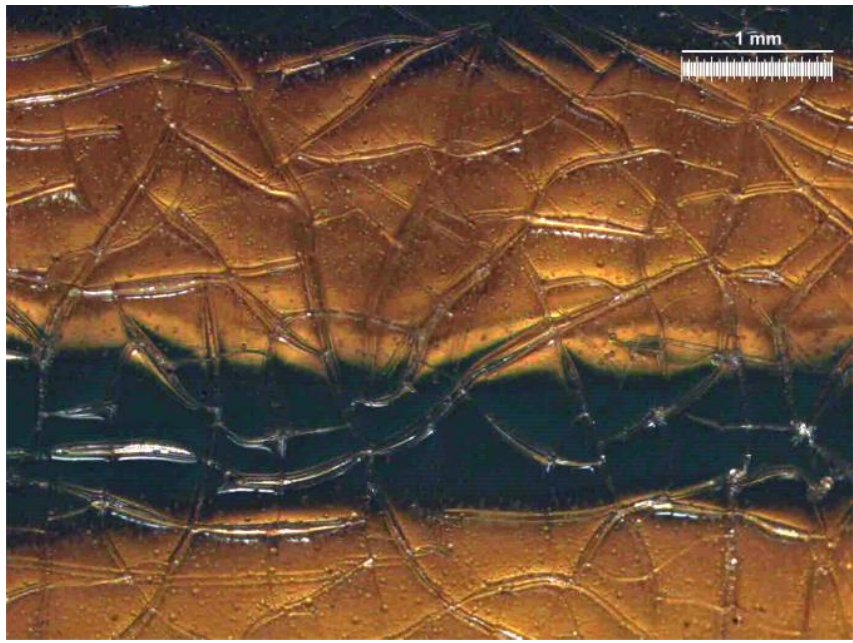

Figure 3.5. Micrograph showing severe damage on a silicone coating during partial discharge aging at $70^{\circ} \mathrm{C}$. Wider fissure-like cracks approximately $100 \mu \mathrm{m}$ wide observed in the top $20 \mu \mathrm{m}$ of the surface.

samples. In this study, the black substance was observed in very reduced quantities, and in some experiments, not at all. This is probably due to the different environmental conditions. At a lower pressure of 500 mbar, the presence of the black substance was reduced considerably and only appeared to accumulate toward the end of the experiment after many hours. At $116 \mathrm{mbar}$, no formations were observed. This would be expected if the black substance was from ambient aerosol, as there would be less of it at lower air densities. No presence of the black substance was observed in the low temperature experiments at ambient pressure. This is probably because of the formation of ice on the surface, later melting and washing away any accumulating formations. At higher temperature, the magnitude of surface damage prevented any observation of these accumulations under microscopy.

While observations of changes in partial discharge inception voltage are readily accounted for as a function of pressure, changes associated with temperature observed here are more difficult to explain. At low temperature, it is possible that the accumulation of surface frost in a very thin layer forms a more conductive layer. This would increase inception voltage, similarly to findings in [8] that suggested accumulating surface pollution from the ambient aerosol reduced surface fields. It is also possible that conductive ambient atmospheric substances that deliquesce into liquid water, or the gaseous by-products (discussed by Sili et al. [7]) that form semi-conducting layers in wet conditions, may be left behind during drying and gradually accumulate to a steady level to achieve a similar result. This may account for the observed gradual increase in inception voltage in the first few microscopy measurements. Experiments at high temperature were raised to $6.0 \mathrm{kV}$ early in the testing cycle to give more consistent partial discharge output on the oscilloscope and to be comparable with that produced at $5.5 \mathrm{kV}$ at $-55^{\circ} \mathrm{C}$. It is thus not clear that a gradual increase in inception voltage would have been observed.

\subsection{FEA ANALYSIS}

Finite element modelling was performed to calculate the peak surface electric fields on boards tested at different voltages for the different experiments. The simulations used a coating thickness of $250 \mu \mathrm{m}$, representing the minimum thickness where no damage was observed either at the lowest tested pressure or the highest temperature. Table 2 shows the corresponding peak surface electric fields above the tracks in each case, and represent the maximum values to ensure minimum observed damage rates from partial discharge for those environmental conditions; exceeding these fields will likely result in degradation. These electric fields ranged between $2.3 \mathrm{kV} \mathrm{mm}^{-1}$ at $116 \mathrm{mbar}$ to $8.3 \mathrm{kV} \mathrm{mm}^{-1}$ at $1000 \mathrm{mbar}$. This is approximately half the field strength modelled in tracking tests where breakdown is occurring, for example [13].

While the model reproduced track curvature based on microscopy of a cross-sectional cut through a test board, sensitivity tests on the effects of the curvature of the track edges on the surface electric fields were made. Increasing track edge curvature increases the local field within the immediate vicinity of the track, but was shown to not significantly affect the field on the coating surface.

\section{CONCLUSIONS}

Experimental investigations on printed circuit boards with high quality, void-free, silicone coatings have characterised and quantified the rate and magnitude of damage resulting from surface partial discharge as a function of pressure and temperature. Partial discharge was generated on board by raising test samples to a high voltage and was not produced externally by corona spray. Samples were left to age for approximately 1 week. The pressures and temperatures involved in testing were chosen to be those relevant to the aerospace industry, ranging down to 116 mbar and up to $70^{\circ} \mathrm{C}$.

Observations support the hypothesis that partial discharge occurs on the surface of samples that have good quality coatings despite higher fields likely within the bulk, in agreement with our previous related study [8] Mechanical stress caused by thermal relaxation may partly contribute to the initiation of some cracks, and silicone bonds on the surface are likely damaged by the partial discharge electrons, in agreement with Kim et al. [12].

Damage on the silicone coatings occurred in the form of surface cracks, with the rate of growth and resulting extent of damage across the surface during the aging period being non-linearly related to coating thickness. Some cracks became wider and fissure-like at higher aging temperatures,

Table 2. Peak surface electric fields that give rise to no observed coating damage, computed using finite element analysis for boards with coating thicknesses of $250 \mu \mathrm{m}$ for the different experiments conducted and their associated test voltages and environmental conditions.

\begin{tabular}{|c|c|c|c|c|}
\hline Test & $\begin{array}{c}\text { Pressure } \\
(\mathbf{m b a r})\end{array}$ & $\begin{array}{c}\text { Temperature } \\
\left({ }^{\circ} \mathbf{C}\right)\end{array}$ & $\begin{array}{c}\text { Operating voltage } \\
(\mathbf{k V})\end{array}$ & $\begin{array}{c}\text { Surface electric field corresponding to no } \\
\text { observable coating degradation }\left(\mathbf{k V} \mathbf{~ m m}^{-1}\right)\end{array}$ \\
\hline 1 & 500 & 20 & 4.0 & 5.5 \\
\hline 2 & 116 & 20 & 1.7 & 2.3 \\
\hline 3 & 1000 & -55 & 5.5 & 7.5 \\
\hline 4 & 1000 & 70 & 6.0 & 8.3 \\
\hline
\end{tabular}


but in all cases, cracks did not penetrate any deeper than $20 \mu \mathrm{m}$ into the surface of the coating. Coating thicknesses less than $100 \mu \mathrm{m}$ lead to the greatest levels of damage, consistent with earlier findings. Reducing pressure was observed to increase damage rate; for coating thicknesses less than $100 \mu \mathrm{m}$, the damage rate at 116 mbar was almost an order of magnitude greater than at ambient pressure (Figure 3.2). Temperature had a considerably greater influence on damage rate. At $-55^{\circ} \mathrm{C}$, very little or no damage was observed; however, at $70^{\circ} \mathrm{C}$, the extent of surface cracking was so substantial that it was not possible to quantify the rate. None of the samples were observed to break down despite a high level of damage, indicating an inherent robustness in good quality silicone coatings. At either low pressures or high temperatures, silicone coating thicknesses greater than $250 \mu \mathrm{m}$ were observed to provide a level of protection from partial discharge activity sufficient to prevent any observable damage during the 160 hours of aging. Finite element analysis was used to identify the corresponding surface electric fields to avoid significant partial discharge degradation under the associated environmental conditions when coating thickness is at least $250 \mu \mathrm{m}$. These are listed in Table 2 .

\section{ACKNOWLEDGMENTS}

The research leading to these results has received funding from the European Union's Seventh Framework Programme $(F P 7 / 2007-2013)$ for the Clean Sky Joint Technology Initiative under grant agreement $\mathrm{n}^{\circ}$ [307309]. The authors also acknowledge the support of project partner Liebherr Elektronik GmbH.

\section{REFERENCES}

[1] F. Paschen, "Ueber die zum Funkenübergang in Luft, Wasserstoff und Kohlensäure bei verschiedenen Drucken erforderliche Potentialdifferenz", Annalen der Physik, vol. 273, pp. 69-96, 1889.

[2] RTCA-DO-160F, "Environmental Conditions and Test Procedures for Airborne Equipment”, ed: RTCA Inc. 1828 L Street, NW, Suite 805 Washington, DC 20035, USA, 2007.

[3] I. Cotton, A. Nelms, and M. Husband, "Defining safe operating voltages for aerospace electrical systems", presented at the Electrical Insulation Conference and Electrical Manufacturing Expo, Nashville, TN, 2007.

[4] I. Cotton, A. Nelms, and M. Husband, "Higher voltage aircraft power systems", Aerospace and Electronic Systems Magazine, IEEE, vol. 23 , pp. 25-32, 2008.

[5] M. Howse, "All electric aircraft", Power Engineer, vol. 17, pp. 3537, 2003.

[6] G. G. Karady, M. D. Sirikis, and J. R. Olivia, "Degrading effect of high-altitude corona on electronic circuit boards", IEEE Transactions on Electrical Insulation, vol. 26, pp. 1216-1219, 1991.

[7] E. Sili, J. P. Cambronne, N. Naudé, and R. Khazaka, "Polyimide Lifetime under Partial Discharge Aging: Effects of Temperature, Pressure and Humidity", IEEE Trans. Dielectr. Electr. Insul., vol. 20, pp. 435-442, 2013.

[8] C. Emersic, R. Lowndes, I. Cotton, S. Rowland, and R. Freer, "Degradation of Conformal Coatings on Printed Circuit Boards due to Partial Discharge", IEEE Transactions on Dielectrics and Electrical Insulation, vol. 23, pp. 2232-2240, Aug 2016.

[9] L. A. Dissado and J. C. Fothergil, "Electrical Degradation and Breakdown in Polymers", IEE Materials and Devices series 9, Published by Peter Peregrinus Ltd, London, United Kingdom, 1992.

[10] D. W. Auckland, A. Taha, and B. R. Varlow, "Correlation of mechanical properties with electrical treeing behaviour at elevated temperatures", presented at the IEEE Conf. Electr. Insul. Dielectr. Phenomena, 1993.

[11] J. V. Champion, S. J. Dodd, A. S. Vaughan, Y. Zhao, and S. J Sutton, "The effect of voltage, temperature and morphology on electrical treeing in polyethylene blends", presented at the 8th Int'l. Conf. Dielectr. Materials, Measurements and Applications, 2000.

[12] H. K. Kim and F. G. Shi, "Thickness Dependent Dielectric Strength of a Low-permittivity Dielectric Film", IEEE Trans. Dielectr. Electr. Insul., vol. 8, pp. 248-252, 2001

[13] F. L. Muhamedin, M. A. M. Piah, and N. A. Othman, "Modelling on Tracking Test Condition of Polymer Nanocomposite using Finite Element Simulation", TELKOMNIKA, vol. 13, pp. 1194-1203, 2015.

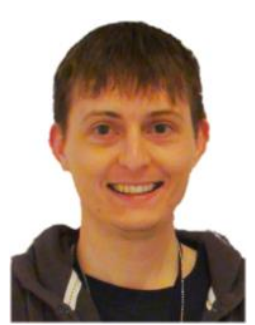

Dr Christopher Emersic was born in the United Kingdom in 1981. He received the MPhys degree from The University of Manchester Institute of Science and Technology (UMIST), UK, in 2003 and $\mathrm{Ph} . \mathrm{D}$. from The University of Manchester, UK in 2006. He has worked as a research associate at the University of Oklahoma, USA, New Mexico Tech, USA, and The University of Manchester, UK. His research interests include thunderstorm electrification and atmospheric electricity, cloud physics, and power electronics.

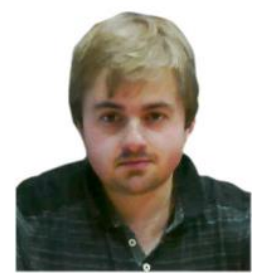

Dr Robert Lowndes was born in Stoke-on-Trent, United Kingdom in 1985. He received a MEng in Materials Science and Engineering from the University of Manchester in 2008 and a PhD in Ceramics and Glasses from the same university in 2012. He has held postdoctoral positions at INCDFM, Romania, and the University of Manchester. His research interests include power electronics, polymer coatings, microwave dielectric ceramics, Raman spectroscopy, and crystallography.

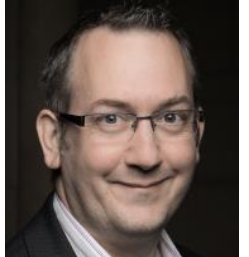

Prof Ian Cotton received a Class I B.Eng. (Hons.) degree in electrical engineering from the University of Sheffield, Sheffield, U.K., in 1995 and the Ph.D. degree in electrical engineering from the University of Manchester, Institute of Technology (UMIST) Manchester, U.K., in 1998. He is currently a Professor of High Voltage Technology at the University of Manchester and the Director of Manchester Energy. His main research interests include power systems transients, the use of higher voltage systems in aerospace applications and power system induced corrosion.

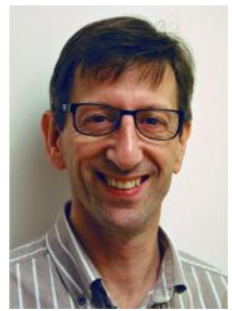

Prof Simon M Rowland (F'14) was born in London, England. He completed the B.Sc. degree in physics at The University of East Anglia, and the $\mathrm{PhD}$ degree at London University, UK. He has worked for many years on dielectrics and their applications and has also been Technical Director within multinational companies. He joined The School of Electrical and Electronic Engineering in The University of Manchester in 2003, and was appointed Professor of Electrical Materials in 2009, and Head of School in 2015. Prof. Rowland was President of the IEEE Dielectric and Electrical Insulation Society from 2011-12.

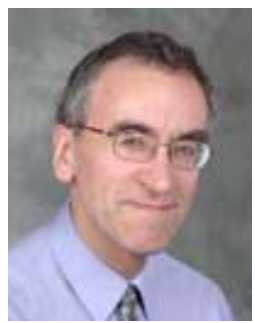

Prof Robert Freer received degrees of BSc, MS and $\mathrm{PhD}$ in Physics from the University of Newcastle upon Tyne, and DSc from University of Manchester, Institute of Technology (UMIST), Manchester, U.K., in 1998. Following postdoctoral work at Strathclyde and Edinburgh Universities he joined the Materials Department of UMIST. He is currently Professor of Ceramics in the School of Materials, University of Manchester. His main research interests are development of functional ceramics, particularly those intended for energy or communications applications. 